Curator of Ornithology at the Natural History Museum of Los Angeles County in California, Dr Schreiber returned for 10 days in June of this year to the island just north of the Equator, to survey the bird population. The survey, financed by the National Science Foundation and The National Geographic Society, is part of a long-term research project on the biology of tropical seabirds, especially as they are affected by the tropical disturbance of the ocean and atmosphere known as El Niño.*

Dr Schreiber found that individuals of most of the 18 species that mysteriously disappeared have returned in small numbers. However, three of the species - the Black or White-capped Noddy (Anous minutus), the Crested Tern (Thalassius bergii), and the Lesser Frigatebird (Fregata oriel) -are breeding in numbers that approach the Island's population prior to the fall of 1982 when the mass abandonment started.

The birds feed exclusively on small fishes and squids which live in the surrounding Pacific Ocean. Earlier this year Dr Schreiber had attributed the mass abandonment to El Niño and the drastic changes it had caused in oceanic and atmospheric conditions which caused the fish population to leave the area, but still he cannot say what the future holds for the birds on the island: 'Ocean and atmosphere scientists are unsure of future directions for the El Niño conditions, and cannot now predict what will happen to the birds in coming months,' Dr Schreiber said. 'The recovery of the bird populations depends on the food supply in the waters surrounding the island.' $\dagger$

* See the account by Professor Klaus Wyrtki of 'Investigation of the El Niño Phenomenon in the Pacific Ocean', published in Environmental Conservation, 2(4), pp. 281-2, 1975.- Ed
Christmas Island, the world's largest coral atoll, is part of the Republic of Kiribati and includes about 200 square miles (518 sq. $\mathrm{km}$ ) of terrain. It is so named because it was discovered on Christmas Eve in 1777 by the English navigator Captain James Cook. The island has a human population of between 1,500 and 2,000 .

\section{RalPH KaZARIAN \\ National Science Foundation $1800 \mathrm{G}$ Street \\ Washington \\ DC 20550, USA.}

\begin{abstract}
†In response to our enquiries, Dr Schreiber wrote most interestingly (in litt. 8 August 1983): ' $\mathrm{El}$ Niño is a recurring phenomenon and I suspect that the birds are adapted to the disappearance of their food. The publicity about our finding the birds gone last fall was a bit sensational. While adults abandoning their young to starve may be sad at first thought, the survival value to the species is evident, and will become more so as we continue to follow up on what is going on. It looks [as though] individual birds have been able to find fish and are starting to breed again. Individual selection seems to be working and this should make Mr Darwin happy.... Three weeks later Dr Schreiber wrote us again: 'We will be going back [to Christmas Island] in October and again in January, March, and June 1984, and are hoping... to continue to follow the situation for the next 3-5 years. We believe this "warm event" is an extremely valuable biological experiment that provides insight into the biological bottlenecks which animal populations must go through. It is now preliminarily obvious that some individuals are able to find food even in times of food stress for the whole population, and that individual selection does operate. It will be most interesting to see what happens over the coming years with the populations which are greatly reduced at present.'-Ed.
\end{abstract}

\title{
Energy Conservation in the Third World: Recommendations of a Workshop
}

The United Nations Environment Programme (UNEP) convened an International Workshop on Energy Conservation in Developing Countries in the Palais des Nations, Geneva, from 21-25 November 1983. The Workshop was attended by experts from Abu Dhabi, Argentina, Brazil, Denmark, Ecuador, Egypt, Finland, France, India, Indonesia, Iraq, Japan, Nigeria, Switzerland, Thailand, USSR, United Arab Emirates, UK, and USA. There were also participants from the Economic Commission for Europe (ECE), the Economic Commission for Western Asia (ECWA), and the Food and Agriculture Organization (FAO).

UNEP presented a draft report to the Workshop on the experience of both developed and developing countries in energy conservation and the measures taken by these countries in that respect. Participants also considered the potential of energy conservation in the Third World, and the environmental, social; and economic, aspects of energy conservation. They agreed that a considerable potential for energy conservation exists in developing countries. Many of these countries were not aware of the contribution that energy conservation might make to their development. Energy conservation schemes would enable developing countries to achieve more than otherwise with their resources, or to achieve their development targets at less cost. Implementation of such schemes would also contribute to the fight against poverty.
The key to the situation lay in integrating energy conservation in overall development plans, rationalizing the use of energy sources, supporting these efforts by adequate legislative and institutional frameworks, providing energy users with an energy-pricing strategy to eliminate waste, allocating funds for investment in, and incentives to, energy efficiency improvements, and establishing programmes of promotion and education as well as information systems to increase awareness of the relevance and importance of energy conservation.

The meeting recommended energy conservation measures in various economic sectors, industry, the buildings and residential sector, transport, agriculture, and power generation. In studying financial constraints, participants emphasized that with the help of effective educational programmes and improved house-keeping, maintenance, and minor reprofiting actions, considerable savings could be achieved in the short term.

General energy conservation measures and action, it was agreed, have positive environmental impacts. However, the environmental aspects of some new technologies for energy conservation should be studied, taking into consideration the prevailing conditions in the Third World.

P.S. When the above official piece was in press we received, from a participant of the Workshop, a first-hand account for which we hope to find space in the Conferences \& Meetings section of our Spring 1984 issue.-Ed. 